\title{
Una versión racionalizada de la doctrina del margen de apreciación estatal
}

\author{
A Rationalized Version of the Doctrine \\ of the Margin of Appreciation of the State
}

Marisa Iglesias Vila*

Recepción : 28/10/2015

Revisiones: 15/03/2016

Recepción y aceptación final: 14/04/2016

Resumen: En este trabajo me centraré en el Tribunal de Estrasburgo por ser la jurisdicción internacional con una doctrina más consolidada sobre el lugar que debe ocupar el criterio estatal en la interpretación y aplicación de un convenio internacional de derechos humanos. Ahora bien, los argumentos que voy a desarrollar en el texto podrían ser también aplicables a otros tribunales internacionales de derechos humanos. Pensemos en la Corte Interamericana de Derechos Humanos (Corte IDH). Aunque su estructura, diseño y circunstancias son distintos, cada vez es mayor el interés académico por las posibilidades de asentar el principio de subsidiariedad y la doctrina del margen de apreciación en el razonamiento de la Corte IDH. Este interés creciente por la doctrina del margen de apreciación en el sistema interamericano es fruto de la evolución tanto de la política regional como del tipo de asuntos sujetos a la jurisdicción de la Corte. A medida que su jurisprudencia

Este trabajo ha sido realizado en el marco del proyecto de investigación DER201348066-C2-2-R (MINECO). Quiero agradecer especialmente a María Eugenia Rodríguez Palop, Aida Torres y Camil Ungureanu sus comentarios y sugerencias, así como las observaciones de los participantes en las diversas conferencias donde he expuesto versiones anteriores de este texto. Universidad Pompeu Fabra.

Correo electrónico: marisa.iglesias@upf.edu 
va transitando hacia la violación cotidiana de derechos humanos en el interior de sistemas democráticos estabilizados, las preguntas acerca de su legitimidad para interferir en el criterio estatal cobran mayor protagonismo. La cuestión es, no obstante, cómo debería conceptualizarse esta doctrina en el contexto de esta evolución para alcanzar un balance adecuado entre democracia y protección de derechos humanos en la región.

Palabras clave: jurisdicción internacional, doctrina margen de apreciación, Estrasburgo, Corte IDH

Abstract: In this paper I will focus on the Strasbourg Court as the international jurisdiction with a more consolidated doctrine with regard to the state approach in the interpretation and application of an international human rights convention. However, the arguments that I am going to develop in the text could also apply to other international human rights courts. Think of the Inter-American Court of Human Rights (CIDH). Although its structure, design and circumstances are different, academic interest in the possibilities of establishing the principle of subsidiarity and the doctrine of margin of appreciation in the reasoning of the IDH Court is growing. This growing interest in the doctrine of margin of appreciation in the inter-American system is the result of the evolution of both regional policy and the type of matters subject to the Court's jurisdiction. As their jurisprudence moves towards the daily violation of human rights within stabilized democratic systems, questions about their legitimacy to interfere with the state's criteria become more prominent. The question is, however, how this doctrine should be conceptualized in the context of this evolution in order to achieve an adequate balance between democracy and human rights protection in the region

Keywords: international jurisdiction, margin of appreciation doctrine, Strasbourg, CIDH

\section{Introducción}

El protocolo n. ${ }^{\circ} 15$ al Convenio Europeo de Derechos Humanos $(\mathrm{CEDH})$, que está en este momento abierto a la ratificación de los Estados parte del Consejo de Europa, va a incorporar por primera vez 
Una versión racionalizada de la doctrina del margen de apreciación estatal

en el preámbulo de este tratado internacional una mención expresa al margen de apreciación de los Estados en la protección de los derechos del Convenio ${ }^{1}$. Esta referencia otorga visibilidad oficial a la doctrina del margen de apreciación nacional, un criterio hermenéutico que el Tribunal Europeo de Derechos Humanos (TEDH) ha desarrollado en su jurisprudencia ${ }^{2}$.

En una declaración conjunta, un grupo de ONG ha criticado este protocolo, mostrando su preocupación porque el preámbulo vaya a mencionar este estándar sin incluir otros principios básicos en la aplicación del Convenio (i. e., protección efectiva, proporcionalidad e interpretación evolutiva) ${ }^{3}$. Su temor es que este paso acabe debilitando el sistema de protección de derechos humanos en Europa. Por esta razón, demandan que sea el Tribunal Europeo de Derechos Humanos la única institución con potestad para definir, desarrollar y aplicar esta doctrina, e insisten en que su alcance debería quedar limitado a los derechos y condicionantes ya estipulados por la jurisprudencia de Estrasburgo.

Cabe augurar que esta reforma aumentará todavía más el protagonismo que ya posee la doctrina del margen de apreciación en el razonamiento del Tribunal Europeo de Derechos Humanos. Teniendo presente, asimismo, el generoso y ambivalente uso que el Tribunal ha efectuado de esta doctrina en algunos ámbitos, la preocupación de las ONG resulta muy comprensible. Partiendo de esta inquietud, en este trabajo examinaré con detenimiento la doctrina del margen de apreciación articulada por Estrasburgo. Primero, introduciré los aspectos básicos de esta doctrina y destacaré algunos claroscuros en su desarrollo por parte del Tribunal. Me detendré, en particular, en

1 Artículo 1, Protocol No. 15 amending the Convention on the Protection of Human Rights and Fundamental Freedoms, Estrasburgo, 24 de junio de 2013.

2 Sobre la Corte IDH y la doctrina del margen de apreciación, véanse, por ejemplo, las diversas contribuciones en Núñez Poblete, M. y Acosta Alvarado, P. A., El margen de apreciación en el sistema interamericano de derechos humanos: proyecciones regionales y nacionales, México: UNAM, 2012; y Contesse, J., "Subsidiarity in Inter-American Human Rights Law”, SELA paper, 2015. www.law.yale.edu/system/files/documents/pdf/SELA15_ Contesse_CV_Eng.pdf.

3 "Protocol 15 to the European Convention on Human Rights Must not Result in a weakening of Human Rights Protection", Joint NGO Statement, 24 de junio de 2013, pp. 2-3. 
su jurisprudencia en torno al uso de simbología religiosa en los centros educativos públicos (arts. 9 del Convenio Europeo de Derechos Humanos y 2 de su Protocolo 1$)^{4}$. Este es uno de los ámbitos donde la doctrina del margen ha jugado un papel determinante en los fallos del Tribunal. Si esta fuera la línea de razonamiento que la reforma del preámbulo acaba incentivando, dejando prácticamente a criterio de los estados la decisión de cuándo una medida restrictiva de derechos humanos es necesaria en una sociedad democrática, el temor expresado por las ONG estaría claramente justificado. Si el margen de apreciación, en contraste, se ajustara a la lógica que el Tribunal ha seguido en el asunto Hirst (art. 3 del CEDH) $)^{5}$ o en materia de derechos de las personas homosexuales y transexuales (arts. 8 y $14 \mathrm{del}$ $\mathrm{CEDH})^{6}$, podría constituir un buen instrumento para equilibrar los

4 El artículo 9 del CEDH reza como sigue: 1. Toda persona tiene derecho a la libertad de pensamiento, de conciencia y de religión; este derecho implica la libertad de cambiar de religión o de convicciones, así como la libertad de manifestar su religión o sus convicciones individual o colectivamente, en público o en privado, por medio del culto, la enseñanza, las prácticas y la observancia de los ritos. 2. La libertad de manifestar su religión o sus convicciones no puede ser objeto de más restricciones que las que, previstas por la ley, constituyen medidas necesarias, en una sociedad democrática, para la seguridad pública, la protección del orden, de la salud o de la moral públicas, o la protección de los derechos o las libertades de los demás. Por su parte, el artículo 2 de su Protocolo 1 prescribe: A nadie se le puede negar el derecho a la instrucción. El Estado, en el ejercicio de las funciones que asuma en el campo de la educación y de la enseñanza, respetará el derecho de los padres a asegurar esta educación y esta enseñanza conforme a sus convicciones religiosas y filosóficas.

5 Hirst c. Reino Unido (n. 2) (6 de octubre de 2005, GS), donde condenó a Gran Bretaña por negar el derecho al voto a los reclusos. El artículo 3 del $\mathrm{CEDH}$ prescribe: Nadie podrá ser sometido a tortura ni a penas o tratos inhumanos o degradantes.

6 Véanse, por ejemplo, X et al. c. Austria (19 de febrero de 2013, GS) y Goodwin c. Reino Unido (11 de julio de 2002, GS). El artículo 8 del CEDH reza como sigue: 1. Toda persona tiene derecho al respeto de su vida privada y familiar, de su domicilio y de su correspondencia. 2. No podrá haber injerencia de la autoridad pública en el ejercicio de este derecho, sino en tanto en cuanto esta injerencia esté prevista por la ley y constituya una medida que, en una sociedad democrática, sea necesaria para la seguridad nacional, la seguridad pública, el bienestar económico del país, la defensa del orden y la prevención del delito, la protección de la salud o de la moral, o la protección de los derechos y las libertades de los demás. Por su parte, el artículo 14 prescribe: El goce de los derechos y libertades reconocidos en el presente Convenio ha de ser asegurado sin distinción alguna, especialmente por razones de sexo, raza, color, 
Una versión racionalizada de la doctrina del margen de apreciación estatal

valores en juego en la aplicación del Convenio. Tras un breve recorrido jurisprudencial, distinguiré dos posibles lecturas de la doctrina del margen de apreciación: una versión "voluntarista" y una versión "racionalizada". Explicaré cuáles serían las ventajas y la dinámica de funcionamiento de la versión racionalizada del margen de apreciación en la argumentación del Tribunal. Por último, usaré los parámetros de esta versión racionalizada para valorar críticamente su jurisprudencia sobre simbología religiosa. Mi objetivo en este trabajo es defender que si el Tribunal adoptara esta versión racionalizada, la mención expresa del margen de apreciación estatal en el preámbulo del Convenio no debería suponer un debilitamiento del sistema general de protección de derechos humanos en la región.

\section{La doctrina del margen de apreciación estatal}

Desde los inicios de su andadura, y ya con mayor articulación desde el asunto Handyside c. Reino Unido, el Tribunal Europeo de Derechos Humanos ha adoptado la doctrina del margen de apreciación con la finalidad de otorgar cierta deferencia al criterio de los Estados en la protección de los derechos del Convenio Europeo de Derechos Humanos $^{7}$. E1 Tribunal ha ofrecido varias razones para justificar esta lógica deferente. Por una parte, ha observado que el sistema de protección de derechos humanos en Europa es fruto de una división del trabajo entre los Estados y el Tribunal Europeo de Derechos Humanos. Los Estados son los responsables primarios de esta protección y Estrasburgo solo

lengua, religión, opiniones políticas u otras, origen nacional o social, pertenencia a una minoría nacional, fortuna, nacimiento o cualquier otra situación.

7 Para una caracterización general de esta doctrina, véanse Arai-Takahashi, Y., The Margin of Appreciation Doctrine and the Principle of Proportionality in the Jurisprudence of the ECHR, Oxford: Intersetia, 2002; Brauch, J., "The Margin of Appreciation and the Jurisprudence of the European Court of Human Rights: Threat to the Rule of Law", Columbia Journal of European Law, v. 11, 2005, pp. 113-150; y Legg, A., The Margin of Appreciation in International Human Rights Law: Deference and Proportionality, Oxford: Oxford University Press, 2012. 
interviene de forma subsidiaria, por vía contenciosa y una vez que se han agotado los recursos judiciales internos. Por otra parte, en ámbitos tan sensibles como la moralidad o la religión no hay consenso entre los Estados en los modos de regulación y las autoridades nacionales, al estar en contacto directo con las fuerzas vitales de su país, se hallan mejor situadas para conocer su coyuntura social y decidir la forma adecuada de gestionar situaciones conflictivas. No obstante, según el propio Tribunal Europeo de Derechos Humanos, este margen es limitado, sujeto a supervisión y variará en función de lo sensible que sea la cuestión a decidir, el tipo de derecho en juego, el carácter más o menos objetivable de los intereses legítimos perseguidos por el Estado y la evolución del consenso europeo en la materia ${ }^{8}$.

Como producto de esta doctrina jurisprudencial, la función judicial que el Tribunal Europeo de Derechos Humanos se arroga no es la de realizar un examen abstracto de compatibilidad entre una medida estatal y las disposiciones del Convenio. Su tarea consiste en revisar si el Estado se ha extralimitado en su margen de apreciación en la protección de derechos convencionales. Ello marca una diferencia importante respecto al tipo de argumentación que podría llevar a cabo un tribunal constitucional nacional. Al mismo tiempo, conlleva una revisión particularizada o en contexto de la medida estatal impugnada, atendiendo a la coyuntura interna de cada país y a sus circunstancias jurídicas, políticas y sociales. Este examen contextual de compatibilidad con el Convenio hace posible que el Tribunal Europeo de Derechos Humanos ofrezca respuestas distintas a casos similares que se producen en coyunturas nacionales diferenciadas.

La doctrina del margen de apreciación ha sido criticada como recurso hermenéutico por dificultar la generalización de las respuestas jurídicas del Tribunal Europeo de Derechos Humanos, provocar incoherencias estructurales y, en general, por poner en peligro la seguridad jurídica e impedir que el Convenio Europeo de Derechos Humanos consolide un sistema fiable de protección de derechos en la 
Una versión racionalizada de la doctrina del margen de apreciación estatal

región ${ }^{9}$. Esta doctrina también ha sido alabada por ser un mecanismo que asegura la flexibilidad argumentativa necesaria para, por un lado, legitimar la autoridad de Estrasburgo frente a la voluntad estatal en la protección de derechos $\mathrm{y}$, por otro, reflejar el pluralismo democrático existente en Europa ${ }^{10}$.

Uno de los ámbitos en los que esta doctrina ha tenido mayor incidencia en los últimos años ha sido en la determinación del alcance del derecho a la libertad religiosa reconocido en el art. 9 del CEDH y en la interpretación del art. 2 de su Protocolo 1, que establece el derecho de los padres a educar a sus hijos conforme a sus convicciones religiosas y filosóficas. Aquí la jurisprudencia de Estrasburgo ha dejado una amplísima autonomía a los Estados para interferir en la libertad religiosa con leyes seculares, ha dado vía libre a la sobreprotección estatal de los sentimientos religiosos mayoritarios frente a la libertad de expresión, ha refrendado las normativas que imponen la presencia de un crucifijo en las escuelas públicas y no ha puesto objeciones a la restricción estatal del uso del velo y otras prendas religiosas en el contexto educativo ${ }^{11}$.

Este trabajo se centrará en dos líneas jurisprudenciales del Tribunal Europeo de Derechos Humanos. Una es la trazada a partir del asunto

9 Brauch, J., "The Margin of Appreciation and the Jurisprudence of the European Court of Human Rights: Threat to the Rule of Law", Columbia Journal of European Law, v. 11, 2005, pp. 113-150; Hutchinson, M., "The Margin of Appreciation and the Jurisprudence of the European Court of Human Rights", International and Comparative Law Quarterly, v. 48, n. 3, 1999, pp. 638-650; y Kratochvíl, J., "The Inflation of the Margin of Appreciation by the European Court of Humans Rights", Netherlands Quarterly of Human Rights, v. 29, n. 3, 2011, pp. 324-357.

10 Especialmente, McGoldrick, D., "Religion in the European Public Square and in European Public Life-Crucifixes in the Classroom?", Human Rights Law Review, v. 11, n. 3, 2011, pp. 451-502; Gerards, J., "Pluralism, Deference and the Margin of Appreciation Doctrine", European Law Journal, v. 17, n. 1, 2011, pp. 80-120; y Mahoney, P., "Marvelous Richness of Diversity or Invidious Cultural Relativism?", Human Rights Law Journal, v. 19, 1998.

${ }^{11}$ Sobre esta jurisprudencia, véanse, por ejemplo, Solar, J. I., "Cautelas y excesos en el tratamiento del factor religioso en la jurisprudencia del Tribunal Europeo de Derechos Humanos", Derechos y libertades, n. 20, 2009, pp. 117-161; y Martínez-Torrón, J., "The (Un)protection of Individual Religious Identity in the Strasbourg Case Law", Oxford: Journal of Law and Religion, (Advance Access), 2012, pp. 1-25. 
Lautsi y otra la que el Tribunal ha adoptado respecto de las normativas nacionales que restringen el uso del velo islámico en los centros educativos públicos. En ambos supuestos, que resumiré a continuación, el uso de la doctrina del margen de apreciación ha jugado un papel trascendental en la orientación de los fallos del Tribunal Europeo de Derechos Humanos.

\section{El margen de apreciación y la simbología religiosa en los centros docentes}

\section{III.1. El asunto Lautsi c. Italia}

En 2011 la Gran Sala del Tribunal Europeo de Derechos Humanos sorprendió a muchos rectificando la sentencia de la Sala del Tribunal que, en 2009, había establecido por unanimidad que la normativa reglamentaria italiana, que impone desde los años 20 la presencia del crucifijo en las escuelas públicas, violaba el derecho de la señora Lautsi a educar a sus hijos conforme a sus convicciones laicas y la libertad religiosa de sus hijos, de 11 y 13 años en ese momento. Los argumentos que la sentencia de la Sala (en adelante, Lautsi 2009) utilizó para justificar la existencia de una violación del Convenio Europeo de Derechos Humanos son un típico ejemplo de una valoración abstracta de compatibilidad entre la normativa italiana y los derechos convencionales. La Sala mantuvo que un crucifijo en un aula pública, en tanto símbolo religioso, podía perturbar emocionalmente a los estudiantes no creyentes y generarles justificadamente la percepción de que su contexto educativo estaba marcado por la religión. Esta intromisión vulnera derechos de libertad religiosa porque contradice el deber de neutralidad estatal en esta materia, que impide al Estado imponer creencias religiosas, aunque sea indirectamente, en contextos de personas especialmente vulnerables o que dependen de él.

El fallo de la Gran Sala (en adelante Lautsi 2011) rectificó esta sentencia inicial matizando sus argumentos e incorporando la doctrina del margen de apreciación en la valoración de la normativa italiana. 
Una versión racionalizada de la doctrina del margen de apreciación estatal

En primer lugar, el Tribunal matizó cuáles son las exigencias convencionales de neutralidad religiosa en el ámbito educativo. Utilizando su jurisprudencia en los asuntos Folguerø y Zengin ${ }^{12}$, indicó que esta exigencia consiste en la prohibición de hacer proselitismo o adoctrinar en el marco educativo, algo compatible con establecer una enseñanza obligatoria de religión y otorgar mayor preponderancia al conocimiento de la religión mayoritaria. En segundo lugar, la Gran Sala defendió que el crucifijo es un símbolo religioso pasivo cuya influencia no puede comparase con la que ejercen la educación y participación en actividades religiosas. Por esta razón, contradijo la sentencia de la Sala y mantuvo que no hay evidencias suficientes ni para afirmar ni para negar que la presencia de este símbolo religioso en las aulas "pueda" afectar a los alumnos o influir en ellos. Aunque reconoció que los padres pueden tener la percepción subjetiva de que un crucifijo supone una falta de respeto a su derecho, esta percepción subjetiva no basta para considerar que hay una vulneración del Convenio ${ }^{13}$. En tercer lugar, la Gran Sala recurrió a la doctrina del margen de apreciación nacional. Según el Tribunal de Estrasburgo, siempre que no haya pretensión de adoctrinamiento, el Estado goza de un margen de apreciación para decidir sobre la permanencia del crucifijo en las aulas. E1 Estado italiano lo considera un aspecto de su tradición y seña de identidad, y le corresponde a él decidir qué peso va a otorgar a la tradición. Le corresponde, asimismo, decidir cómo va a compatibilizar el lugar que asigne a la religión en el entorno educativo con los derechos de padres y estudiantes. El Tribunal Europeo de Derechos Humanos consideró que en apoyo de este margen está también la falta de consenso entre

12 Folguerø c. Noruega (29 de junio de 2007, GS) y Zengin c. Turquía ( 9 de octubre de 2007).

${ }^{13}$ Lautsi 2009 había utilizado el asunto Dahlab (donde en 2001 el TEDH confirmó que era compatible con el Convenio que las autoridades suizas impidiesen a una profesora de una escuela pública llevar velo en clase) para apoyar la idea de que los símbolos religiosos pueden afectar a los niños. Pero el TEDH resaltó ahora que Dahlab era un caso diferente, donde el derecho nacional asumía la neutralidad denominacional en materia religiosa y, dada la tierna edad de los niños (4 a 8 años), la prohibición entraba dentro de su margen de apreciación. 
los Estados sobre la presencia de símbolos religiosos en las escuelas públicas y sobre el mantenimiento de las tradiciones. Por último, aunque la Gran Sala admitió que el crucifijo otorga mayor visibilidad a la religión católica en el entorno escolar, indicó, aplicando de nuevo la doctrina del margen de apreciación, que este extremo debe ponerse en perspectiva teniendo presente cuál es la actitud del Estado italiano ante el pluralismo religioso en las escuelas. En el caso de Italia, el crucifijo no está vinculado a ninguna enseñanza obligatoria de la religión católica, el ambiente escolar está abierto a otras religiones, no se impide que los alumnos usen otros símbolos religiosos como el velo, se permiten celebraciones de otras religiones y podría haber educación religiosa alternativa para todos los credos. Todos estos elementos le parecieron suficientes a la Gran Sala para concluir que el Estado italiano estaba respetando el pluralismo religioso en las escuelas, que la señora Lautsi seguía pudiendo ejercer el derecho a educar a sus hijos de conformidad con sus creencias y que la libertad religiosa negativa de sus hijos no había sido vulnerada.

Tanto Lautsi 2009 como Lautsi 2011 han sido ampliamente criticadas. La primera lo ha sido por imponer un modelo de laicismo estricto que no respeta ni el pluralismo de tradiciones existente en Europa ni su diversidad de relaciones estado-religión, pero también por exceder las competencias del Estrasburgo en la protección de los derechos del Convenio $^{14}$. La Sentencia de la Gran Sala, en cambio, ha sido criticada por suponer un retroceso para el laicismo en Europa, tener un mero carácter político, ceder a las presiones de algunos Estados e instituciones europeas y, en general, por suponer una dejación de funciones por parte del Tribunal Europeo de Derechos Humanos ${ }^{15}$.

${ }^{14}$ Sobre estas críticas véase, especialmente, McGoldrick, D., "Religion in the European Public Square and in European Public Life-Crucifixes in the Classroom?", Human Rights Law Review, v. 11, n. 3, 2011, pp. 451-502. También fue bienvenida por ser un paso valiente del TEDH en defensa del laicismo, la neutralidad estatal y la protección de las minorías religiosas en Europa. Véase Andreescu, G. y Andreescu, L., "The European Court of Human Rights' Lautsi Decision: Context, Contents, Consequences", Journal for the Study of Religions and Ideologies, v. 9, n. 26, 2010, pp. 47-74.

${ }^{15}$ Sobre estas objeciones véanse, entre otros, Panara, C., "Another Defeat for the Prin- 
Una versión racionalizada de la doctrina del margen de apreciación estatal

Con independencia ahora de estas críticas, lo cierto es que la principal diferencia entre ambas resoluciones reside en el rol que desempeña la doctrina del margen de apreciación estatal en la decisión final de la Gran Sala, recurso hermenéutico que está ausente en Lautsi 2009. ¿Está justificado el amplio uso que la Gran Sala realiza de esta doctrina? Antes de entrar a valorar esta cuestión me detendré brevemente en la segunda línea de decisiones que comentaba anteriormente.

\section{III.2. La jurisprudencia del Tribunal Europeo de Derechos Huma- nos sobre el velo islámico en el contexto educativo}

La restricción del uso del velo y otras prendas religiosas en los centros educativos públicos ha generado una extensa controversia en Europa, polémica que la jurisprudencia del Estrasburgo ha zanjado siempre acogiendo el criterio estatal ${ }^{16}$. Las normativas francesa y turca, que abogan por un laicismo militante que es restrictivo con la expresión religiosa en el espacio público, son las que han generado mayor número de recursos ante el Tribunal Europeo de Derechos Humanos, muchos de los cuales no han sido admitidos a trámite por estar "manifiestamente" mal fundados. De esta jurisprudencia cabe extraer que los Estados tienen autonomía para limitar el uso del velo y otras prendas religiosas en algunas clases o en todas, tanto en la escuela pública como en la universidad; esta restricción puede abarcar a profesoras y puede extenderse a escuelas de base religiosa islámica financiadas por el Estado. Los argumentos que se han considerado legítimos y proporcionados para justificar limitaciones en el uso escolar del velo son muy variados. La razón más genérica es el laicismo de Estado (asuntos

ciple of Secularism: Recent Developments on the Display of the Crucifix in Italian Courtrooms", Religion and Human Rights, v. 6, n. 3, 2011, pp. 259-265; y Zuca, L., "Lautsi: A Commentary on a Decision by the ECtHR Gran Chamber", International Journal of Constitutional Law, v. 11, n. 1, 2013, pp. 218-229.

16 Asuntos Dahlab c. Suiza (15 de febrero de 2001), Şahin c. Turquía (10 de noviembre de 2005, GS), Köse y 93 más c. Turquía (4 de noviembre de 2006), Kervanci c. Francia y Dogru c. Francia (4 de diciembre de 2008) y Aktas c. Francia, Bayrak c. Francia, Gamaleddyn c. Francia y Ghazal c. Francia (30 de junio de 2009). 
Kervanci, Dogru, Şahin, Köse y Dahlab). También, de forma general, se ha apelado a razones de orden público, a los derechos de otros y a la defensa de la democracia (especialmente en el asunto Şahin). Finalmente, otros argumentos que han sido utilizados como razón para prohibir el uso del velo son la promoción de la igualdad de género (asuntos Dahlab y Şahin) y consideraciones de higiene y seguridad en la práctica del deporte (asuntos Kervanci y Dogru).

En el asunto Şahin c. Turquía, que es en el que me detendré brevemente, la polémica se originó a partir de una circular de la autoridad académica de la Universidad de Estambul prohibiendo el uso del velo islámico dentro del recinto. A partir de entonces, a la recurrente, ya en sus últimos años de estudio de la carrera de medicina y habiendo usado el velo en la universidad hasta ese momento, se le impidió examinarse y matricularse en algunos cursos por seguir llevando velo.

Al igual que en el resto de asuntos relativos al velo islámico, los argumentos de Estrasburgo para refrendar esta restricción a la libertad religiosa en la universidad están orientados por un recurso constante a la doctrina del margen de apreciación. El Tribunal asocia la necesidad de usar esta doctrina a la ausencia de un consenso europeo en esta materia y a la idea de que el Estado y las autoridades universitarias están mejor situados que un órgano internacional para decidir sobre esta polémica. Aunque el Tribunal recuerda el deber estatal de neutralidad religiosa e indica que su función en este caso consiste en corroborar si la medida institucional está justificada en principio y es proporcionada, no observa ninguna dificultad para validar convencionalmente los argumentos aportados por Turquía. Apoyándose en la doctrina del margen, el Tribunal asume, en primer lugar, que la opción política por el laicismo de Estado puede justificar por sí misma restricciones a la libertad religiosa y exigir sacrificios a los individuos en aras de salvaguardar la tolerancia y la armonía religiosa. En segundo lugar, elude valorar en detalle la aplicabilidad al caso concreto de las alegaciones generales del estado turco: el peligro del islamismo radical para el orden público y la democracia, el respeto por la igualdad de género y la protección de los derechos del resto de los estudiantes. El Tribunal Europeo de Derechos Humanos considera que el laicismo de Estado 
Una versión racionalizada de la doctrina del margen de apreciación estatal

junto con estos argumentos generales resultan suficientes para considerar que la prohibición, aunque restringe la libertad religiosa de Leyla Şahin, no vulnera el Convenio Europeo de Derechos Humanos ${ }^{17}$.

\section{Dos versiones de la doctrina del margen de apreciación estatal}

De forma paralela a lo que sucede en el asunto Lautsi, la jurisprudencia sobre el velo islámico es un ejemplo de la importancia de la doctrina del margen de apreciación en la forma de razonar y valorar las restricciones estatales a los derechos convencionales por parte de Estrasburgo. Por lo que respecta al velo, no solo teóricos sino también organizaciones de derechos humanos han denunciado reiteradamente que este razonamiento comporta una clara desprotección del derecho a la libertad religiosa en Europa. E1 razonamiento del Tribunal Europeo de Derechos Humanos en el asunto Lautsi ha recibido críticas similares. Sin embargo, como ya he mencionado, muchos otros defienden que este razonamiento deferente es el vehículo adecuado para que esta institución internacional mantenga una narrativa constitucional sin perder legitimidad frente a los Estados.

Estemos de acuerdo con unos o con otros, lo cierto es que el Tribunal de Estrasburgo está ejerciendo su función de interpretar el Convenio buscando legitimarse sin renunciar a la calidad sustantiva en sus decisiones. Esta pretensión conciliadora parece ser inherente al propio Convenio desde el momento en que su preámbulo afirma que el mantenimiento de las libertades y derechos básicos que contiene reposa, de un lado, en un régimen político verdaderamente democrático y, de otro, en una concepción y respeto comunes de los derechos humanos. Esta dualidad axiológica podría contemplarse como una de las especificidades del Convenio en tanto objeto jurídico de interpretación,

17 Cabe advertir que el Tribunal (pár. 78) tampoco mostró estar convencido de que llevar el velo islámico fuera un acto de manifestación de práctica religiosa y no un mero acto inspirado o motivado por una religión, acto que no estaría protegido por el art. 9. 
característica que, por tanto, debería estar presente en cualquier teoría normativa de adjudicación en el marco de este instrumento ${ }^{18}$.

La cuestión es no obstante si el Tribunal ha tenido éxito en este empeño conciliador en su jurisprudencia sobre simbología religiosa. En el asunto Lautsi la estrategia de la Gran Sala, que ha sido determinante para su fallo, es desplazar la cuestión de si se ha afectado de forma injustificada el foro interno de la libertad religiosa. Derecho que el texto del Convenio no sujeta a restricciones de interés público, sino a una cuestión de si el Estado ha sido suficientemente neutral en el respeto al pluralismo religioso de sus ciudadanos en el ejercicio de su margen de apreciación. Este desplazamiento permite al Tribunal entrar a valorar en concreto la importancia que el crucifijo pueda poseer como tradición cultural y signo de identidad colectiva en Italia. También le permite poner en contexto la normativa italiana analizando en qué medida su entorno educativo está abierto al pluralismo religioso. La Gran Sala acaba utilizando lo que se ha denominado una "teoría de la neutralización", que resalta aquellos aspectos en los que el sistema educativo italiano es equitativo en su apertura al pluralismo religioso en la escuela para contrarrestar su falta de neutralidad con la religión mayoritaria respecto a la simbología ${ }^{19}$. También en el asunto Şahin el Tribunal Europeo de Derechos Humanos utiliza una estrategia equiparable cuando evita entrar en un examen detallado de proporcionalidad, que es a lo que le exhorta el artículo 9.2 del Convenio Europeo de Derechos Humanos, y se decanta por asumir de forma más bien acrítica las razones generales aportadas por el Estado turco.

Estos equilibrios de Estrasburgo para aplicar la doctrina del margen en la gestión doméstica del pluralismo religioso han conducido a una jurisprudencia con un alto grado de incoherencia axiológica que va en detrimento del principio convencional de protección efectiva ${ }^{20}$.

${ }^{18}$ Especialmente, Arai-Takahashi, Y., The Margin of Appreciation Doctrine and the Principle of Proportionality in the Jurisprudence of the ECHR, Oxford: Intersetia, 2002, p. 243.

19 Andreescu, G. y Andreescu, L., "Taking Back Lautsi: Towards a 'Theory of Neutralisation'?", Religion and Human Rights, 2010, pp. 207-212.

20 Sobre su tratamiento general del factor religioso, véanse, Martínez-Torrón, J., "Los límites de la libertad de religión y de creencia en el Convenio Europeo de Derechos 
Una versión racionalizada de la doctrina del margen de apreciación estatal

Ahora bien, esta incoherencia es más fiel a los desacuerdos valorativos existentes entre los Estados que la alternativa de un juicio abstracto de compatibilidad. Otorgar un margen amplio al Estado en materia religiosa podría apoyarse en dos elementos de esta doctrina, la falta de consenso y la idea de que el Estado está mejor situado para resolver conflictos sobre simbología religiosa en los centros educativos. Pero el Tribunal ha sido muy errático en la importancia que ha otorgado a estos factores, desdibujando su posible efecto legitimador. ¿Debería el Tribunal Europeo de Derechos Humanos haberse distanciado en estos casos de la doctrina del margen de apreciación?

Para valorar adecuadamente esta cuestión es importante distinguir dos versiones de esta doctrina ${ }^{21}$. La primera es una versión que podríamos denominar "voluntarista". Parte de que el Tribunal Europeo de Derechos Humanos es un órgano internacional y asume una visión normativa y no meramente formal del principio de subsidiariedad ${ }^{22}$. Desde esta perspectiva, el Tribunal reconoce que su legitimidad política es meramente derivada y otorga una fuerte presunción de partida a favor del Estado, evitando realizar una valoración independiente de compatibilidad entre las medidas impugnadas y el Convenio. Esta pre-

Humanos", RGDCDEE, n. 2, 2003; ídem 2012; Solar, ídem. Sobre el principio convencional de protección efectiva como un principio central que da sentido al CEDH véase Greer, S., "Constitutionalizing Adjudication under the European Convention on Human Rights", Oxford Journal of Legal Studies, v. 23, n. 3, 2003, pp. 405-433.

${ }^{21}$ La distinción que propondré a continuación entre dos versiones de la doctrina del margen de apreciación es similar en muchos aspectos a la distinción que adopta Letsas entre un concepto estructural y un concepto sustantivo del margen de apreciación. Ver Letsas, G., "Two Concepts of the Margin of Appreciation", Oxford Journal of Legal Studies, v. 26, n. 4, 2006, pp. 705-732.

${ }^{22}$ Una visión formal o procedimental del principio de subsidiariedad incide en que el Tribunal de Estrasburgo solo interviene en la protección de derechos convencionales por vía contenciosa y una vez se han agotado los remedios internos. Una visión normativa de este principio, en cambio, que en este ámbito suele tener un sesgo estatista, proclama la prioridad de las decisiones nacionales en caso de una eventual divergencia con el criterio de la autoridad supranacional. Sobre esta distinción véase especialmente Letsas (ver Letsas, ídem). Para diversas concepciones normativas de la subsidiariedad véase, también, Føllesdal, A., "The Principle of Subsidiarity as a Constitutional Principle in International Law", Global Constitutionalism, v. 2, n. 1, 2013, pp. 37-62. 
sunción solo se rompe cuando hay razones especialmente sólidas para concluir que el Estado se ha extralimitado en el ejercicio de su autonomía. En esta versión del margen, factores como la falta de consenso europeo o la idea de que el Estado está mejor situado adquieren importancia por razones generales de legitimidad institucional. En consecuencia, cabría afirmar que cuando el Tribunal se pregunta aquí si un Estado ha violado el Convenio lo que realmente se está preguntando es si tiene legitimidad política para adoptar una determinada decisión.

La versión voluntarista del margen (en adelante VVM) es la que cabe encontrar detrás de la oposición pública que recibió Lautsi 2009 por parte de muchos estados del Consejo de Europa y otras instituciones europeas. La opinión de Dominic McGoldrick expresa bien la lógica de la VVM cuando afirma que Estrasburgo debe poseer una antena política porque

judicial authority ultimately depends on the confidence of citizens and there is no real link between the European judges and the European population. If the Court's interpretations deeply differ from the convictions of the people, the people (and their governments) will start resisting judicial decisions ${ }^{23}$.

La segunda es una versión racionalizada del margen de apreciación estatal (en adelante VRM). La doctrina del margen se percibe ahora como el resultado de efectuar un balance entre los valores en juego en la protección de derechos convencionales más que una presunción fuerte de partida a favor del Estado. Esta concepción dirige el razonamiento del Tribunal Europeo de Derechos Humanos a examinar si la medida estatal impugnada consigue alcanzar un balance equitativo entre derechos individuales y valores democráticos. Desde esta lógica, la argumentación del Tribunal no tiene por qué estar mediatizada por consideraciones generales acerca de su legitimidad institucional ni la voluntad estatal tiene por qué adquirir un valor independiente. Su valor será funcional al éxito del estado en conseguir este equilibrio axioló-

${ }^{23}$ McGoldrick, ídem.; Gerards, ídem. En esta misma línea se ubica la airada reacción de David Cameron frente a la sentencia de la Gran Sala en el asunto Hirst. 
Una versión racionalizada de la doctrina del margen de apreciación estatal

gico inherente a una sociedad democrática. La finalidad de la VRM no es simplemente la justificación de la "deferencia" al Estado sino el reconocimiento equilibrado de los valores democráticos en el seno del Convenio Europeo de Derechos Humanos. Esta versión racionalizada es, por ejemplo, la que inspira las cláusulas de acomodación de los artículos 8 a 11 del Convenio (disposiciones que, en su primer apartado, reconocen derechos para proceder, en un segundo apartado, a detallar un conjunto de razones que justifican su restricción por parte del Estado ${ }^{24}$. También es la que parece ajustarse a la dualidad axiológica expresada en el preámbulo de este tratado internacional. En suma, la versión racionalizada se concentra en la axiología interna al Convenio mientras que la versión voluntarista tiende a unir esta doctrina con consideraciones externas de facticidad política.

La adopción de una versión voluntarista, algo bastante habitual en materia de libertad religiosa, es cuestionable porque conduce al Tribunal a renunciar a su rol jurisdiccional más que a consolidar su legitimidad institucional ${ }^{25}$. Una jurisprudencia tan apegada a las coyunturas y particularidades estatales es preocupante porque impide al Tribunal Europeo de Derechos Humanos articular un marco estable de mínimos convencionales que defina el contorno de la libertad estatal en la gestión de su pluralismo religioso interno. El asunto Lautsi y la jurisprudencia sobre el velo reflejan esta dejación de funciones. El giro abrupto de la Gran Sala respecto a Lautsi 2009, su distanciamiento ad hoc del criterio usado en Dahlab y el desplazamiento del objeto de discusión muestran la ausencia de este marco de mínimos que permita valorar el margen que cabe otorgar al Estado italiano sin caer en la mera concesión política. Algo parecido sucede con las prohibiciones del velo y la renuencia del Tribunal a examinar detalladamente la proporcionalidad de las razones aportadas. La versión voluntarista usada en estos

${ }^{24}$ En la aplicación de las cláusulas de acomodación, el TEDH valora la medida impugnada siguiendo siempre la misma estructura de cuestiones: 1) ¿Hay interferencia estatal en un derecho convencional? 2) ¿Esta interferencia está prescrita por el Derecho? 3) ¿Tiene un fin legítimo? y 4) ¿La medida es proporcionada y necesaria en una sociedad democrática para conseguir este fin?

${ }^{25}$ Especialmente, Brauch, ídem; y Solar, ídem. 
asuntos, dado su déficit de fundamento axiológico, corre el peligro de acabar en un "casi todo vale" para los Estados.

Con anterioridad al reconocimiento oficial de esta doctrina, los defectos de una versión voluntarista habían provocado una línea de opinión entre comentaristas y jueces de este órgano internacional que abogaban por la conveniencia de que el Tribunal abandonara este recurso hermenéutico ${ }^{26}$. Pero ahora podemos augurar que esta doctrina está aquí para quedarse, y ello no es solo un reflejo de la presión que han ejercido los Estados cuando el criterio nacional ha sido cuestionado por el Tribunal Europeo de Derechos Humanos. Los Protocolos 14, 15 y 16 al Convenio Europeo pretenden mejorar el sistema de supervisión de Estrasburgo, y las reformas que se han articulado, entre ellas la del preámbulo, y obedecen también a la necesidad de disminuir la gran cantidad de asuntos que en los últimos años están alcanzando la jurisdicción del Tribunal.

Mi sugerencia es que la versión racionalizada, a diferencia de la voluntarista, puede constituir un recurso hermenéutico con las virtudes necesarias para ser incorporado de modo permanente en la jurisprudencia de Estrasburgo. Al mismo tiempo, esta versión de la doctrina podría tener funcionalidad más allá de las cláusulas de acomodación, sustituyendo de modo general, es decir, para todos los derechos convencionales, el análisis abstracto de compatibilidad en el razonamiento del Tribunal. Pero en este trabajo solo me detendré en explicar cuál sería su dinámica de funcionamiento centrándome en la jurisprudencia sobre simbología religiosa en los centros educativos públicos.

${ }^{26}$ Por ejemplo, Brauch (ver Brauch, ídem), quien insiste en que el TEDH debe ceñirse a la letra del Convenio; Martínez-Torrón (ver Martinez- Torrón, ídem). En este sentido se expresa también el juez De Mayer en su opinión parcialmente disidente en el asunto Z. c. Finlandia (25 de febrero de 1997). 
Una versión racionalizada de la doctrina del margen de apreciación estatal

\section{La dinámica de una versión racionalizada del margen de apreciación estatal}

La versión racionalizada podría funcionar como recurso hermenéutico general en el razonamiento de Estrasburgo en materia de libertad religiosa bajo ciertas premisas previas que marcan su función jurisdiccional. Por una parte, debemos asumir que la finalidad del Convenio Europeo de Derechos Humanos, en tanto instrumento coadyuvante en el afianzamiento de la democracia en la región, es consolidar un umbral "mínimo" de calidad formal y sustantiva en la protección de derechos en el seno del Consejo de Europa. Sin embargo, ello no implica, como observa Michael Hutchinson, que la labor del Tribunal en cada uno de sus fallos consista en ir concretando, según su criterio, cuál es este umbral mínimo de protección universal. Si ese fuera el caso no sería necesario realizar ningún tipo de balance con otras consideraciones y la ponderación efectuada por el Estado no adquiría realmente ninguna trascendencia; el Tribunal Europeo de Derechos Humanos se encargaría de decidir cuál es este mínimo y el resto quedaría en manos de las autoridades nacionales. El problema sigue siendo que este mínimo no se determina en abstracto. En consecuencia, tendrá cierto grado de movilidad y sus contornos seguirán dependiendo de un equilibrio entre democracia y derechos ${ }^{27}$.

Por otra parte, las disposiciones que encontramos en un instrumento internacional como el Convenio Europeo de Derechos Humanos distan mucho de reflejar una comprensión moral robusta de los derechos convencionales. Muchos de ellos están sujetos a cláusulas de limitación, todas ellas muy amplias, y en general la lógica dual del Convenio hace difícil defender una caracterización de los derechos convencionales como triunfos, side constraints o consideraciones reason-blocking ${ }^{28}$. Incluso,

${ }^{27}$ Véase Hutchinson, ídem. También Brems, E., "Human Rights: Minimum and Maximum Perspectives", Human Rights Law Review, v. 9, n. 3, 2009, pp. 349-372.

${ }^{28}$ Sobre las diversas formas de comprender los derechos convencionales, véanse, por ejemplo, McHarg, A., "Reconciling Human Rights and the Public Interest: Conceptual Problems and Doctrinal Uncertainty in the Jurisprudence of the European Court of Human Rights", The Modern Law Review, v. 62, 1999, pp. 671-696; Greer, ídem; 
si comprendemos estos derechos jurídicos desde su fundamento en el discurso de los derechos humanos, solo una concepción ética de estos últimos apoyaría su carácter de triunfos ${ }^{29}$. Pero la concepción ética está recibiendo un fuerte embate desde otras aproximaciones alternativas que pretenden ajustar la noción de derecho humano a su rol de razones para la acción dentro la práctica internacional. Para estas concepciones funcionales o políticas, la identificación de estos derechos no depende solo de su contenido sino, también, de contingencias y factores de viabilidad, efectividad y legitimidad institucional que son relevantes para limitar la soberanía estatal y justificar actuaciones en el ámbito internacional. En este sentido, si los derechos convencionales son vistos como razones para justificar la acción dentro del sistema del Convenio, la propia identidad de estos derechos incorporará un ejercicio de balance entre razones de diferente carácter ${ }^{30}$.

Desde estas dos premisas, podemos regresar a la función que la versión racionalizada atribuye al Tribunal de Estrasburgo. Mencioné, anteriormente, que su función es supervisar el equilibrio axiológico de los Estados frente a las demandas de protección de derechos por parte

Kumm, M., "What Do You Have in Virtue of Having a Constitutional Right? On the Place and Limits of the Proportionality Requirement", en Paulsen, S. y Pavlakos, G. (eds.), Law, Rights, and Discourse: Themes of the Work of Robert Alexy, Oxford: Hart Publishing, 2007; Legg, ídem.

${ }^{29}$ La noción de derechos como triunfos, esto es, la idea de que los derechos son un triunfo frente al interés colectivo por su carácter de razones que, en situaciones regulares, no son susceptibles de balance con otras consideraciones externas a las propios derechos proviene de Dworkin. Ver Dworkin, R., Taking Rights Seriously, Cambridge: Harvard University Press, Mass, 1977, p. 191, 194, 197-200.

${ }^{30}$ Véase, especialmente, Raz, J., "Human Rights without Foundations", Oxford Legal Studies Research Papers, n. 14, 2007, pp. 1-20; "Human Rights in the Emerging World Order", Transnational Legal Theory, n. 1, 2010, pp. 31-47. Sobre las diferencias entre una concepción ética y una concepción política de los derechos humanos, véanse, también, Beitz, Ch., The Idea of Human Rights, Oxford: Oxford University Press, 2009; Baynes, K., "Toward a Political Conception of Human Rights", Philosophy and Social Criticism, n. 35, 2009, pp. 372-373; Iglesias Vila, M. y Ungureanu, C., "The Conundrum of Pluralism and the Doctrine of the Margin of Appreciation: The Crucifix 'Affair' and the Ambivalence of the ECtHR", en Requejo, F. y Ungureanu, C. (eds.), Democracy, Law and Religious Pluralism in Europe: Secularism and Post-Secularism, Londres: Routledge, 2012, pp. 179-199. 
Una versión racionalizada de la doctrina del margen de apreciación estatal

de sus ciudadanos. Pero su función es también sistémica. El Tribunal Europeo de Derechos Humanos tiene la tarea de consolidar una estructura jurídica de protección de derechos en Europa que pueda constituir una guía general de actuación para los Estados. ¿Qué elementos o variables aportaría esta versión del margen de apreciación en el razonamiento del Tribunal Europeo de Derechos Humanos para llevar a cabo estas funciones?

Un elemento básico en la valoración de una medida estatal restrictiva de derechos ponderables es el uso del principio de proporcionalidad. Ya he comentado que en materia religiosa es muy frecuente que el Tribunal Europeo de Derechos Humanos minimice su examen de proporcionalidad y recurra a la versión voluntarista. Ello le permite deferir al criterio estatal en la determinación de cuándo una restricción a la libertad religiosa es necesaria dentro de una sociedad democrática ${ }^{31}$. Son muchos los que reclaman que el Tribunal Europeo de Derechos Humanos debería aplicar un test más estricto de proporcionalidad que actúe como límite a la discreción del Estado. Pero la cuestión es cómo la versión racionalizada orientaría este escrutinio de proporcionalidad.

Una vez que constatamos que una medida restrictiva de derechos persigue un fin legítimo, el análisis de proporcionalidad se suele concebir como el examen de tres cuestiones: 1) si la medida es "idónea" para alcanzar el fin, 2) si es "necesaria" para obtener ese fin (si había otras alternativas menos restrictivas para alcanzar el fin con la misma eficacia) y 3) si es proporcional en sentido estricto, es decir, si es equilibrada respecto al grado de afectación del derecho y el grado de satisfacción del interés colectivo que se persigue. Este test, denominado habitualmente test alemán de proporcionalidad, es usado por muchos tribunales constitucionales y también, con mayor o menor profundidad, por el Tribunal de Justicia de la Unión Europea ${ }^{32}$. Pero el Tribunal

${ }^{31}$ Sobre esta minimización del examen de proporcionalidad, véase Martínez-Torrón, ídem.

32 Para la dinámica del examen de proporcionalidad, véanse, en general, Alexy, R., Teoría de los derechos fundamentales, Madrid: Centro de Estudios Políticos y Constitucionales, 1993; Klatt, M. y Meister, M., The Constitutional Structure of Proportionality, Oxford: Oxford University Press, 2012; Barak, A., Proportionality: Constitutional Rights and their Limitations, Cambridge: Cambridge University Press, 2012. 
de Estrasburgo no se ha involucrado en un examen tan estructurado para entender las exigencias convencionales del principio de proporcionalidad. Cuando ha mencionado este principio en el momento de juzgar si la medida estatal restrictiva de derechos era "necesaria en una sociedad democrática", su razonamiento ha girado en torno a cuestiones como la de si hay una necesidad social imperiosa (pressing social need), si la restricción al derecho ha sido la mínima posible en atención a las alternativas disponibles para el Estado y si se ha alcanzado un balance equitativo (fair balance) entre el fin legítimo y el derecho ${ }^{33}$. Estas cuestiones, sin embargo, no han sido valoradas conjunta o consecutivamente por parte del Tribunal.

Sin cuestionar ahora esta visión algo difusa del principio de proporcionalidad, la primera pretensión de una versión racionalizada, a diferencia de lo que suscribiría una versión voluntarista, es que el Tribunal Europeo de Derechos Humanos se embarque efectivamente en una valoración de proporcionalidad de la medida impugnada. Esto supone un paso importante en la protección efectiva de los derechos convencionales frente a la voluntad estatal. Ahora bien, dado que sigue siendo una doctrina del margen de apreciación, la versión que defiendo asume que en el examen de proporcionalidad es necesario equilibrar tanto razones de primer orden como razones de segundo orden ${ }^{34}$. Así, en el momento de resolver un eventual conflicto entre derechos convencio-

${ }^{33}$ En el asunto Handyside c. Reino Unido, pár. 48, el TEDH interpreta la idea de "necesaria para una sociedad democrática" no en el sentido de indispensable o absolutamente necesaria, sino utilizando la terminología "pressing social need". También asume que le corresponde al Estado, en aplicación de la doctrina del margen de apreciación, la valoración inicial de esta necesidad social imperiosa. Como observa Greer, la exigencia de que haya una necesidad social imperiosa permite otorgar prioridad a los derechos frente a las finalidades colectivas porque impone al Estado la carga de probar esa necesidad imperiosa. Ver Greer, ídem. Sobre el principio de proporcionalidad y el resto de cuestiones que se valoran en el razonamiento del TEDH, véanse, también, Arai-Takahashi, ídem; Spielmann, D., "Allowing the Right Margin the European Court of Human Rights and the National Margin of Appreciation Doctrine: Waiver or Subsidiarity of European Review?", CELS Working Paper Series, 2012, pp. 1-30; y Legg, ídem.

${ }^{34}$ Sobre la importancia de las razones de segundo orden en la valoración del margen de apreciación estatal, véase, especialmente, Legg, A., ídem. 
Una versión racionalizada de la doctrina del margen de apreciación estatal

nales e intereses colectivos, este examen no debería guiarse solamente por razones de contenido y consideraciones particulares de adecuación y necesidad de la medida impugnada, sino, también, teniendo presentes razones vinculadas al sentido y lógica general del sistema europeo de protección de derechos humanos ${ }^{35}$. A continuación, ofreceré algunos detalles de cómo podrían actuar estas razones sistémicas.

En primer lugar, es razonable que en el examen de proporcionalidad el Tribunal tenga presente el marco general de protección que el Estado ofrece al derecho individual que ha restringido. Esta consideración adquiere trascendencia cuando asumimos que la protección de derechos convencionales es fruto de una división del trabajo entre los Estados y el Tribunal Europeo de Derechos Humanos, con lo que la intervención de Estrasburgo tiene un carácter subsidiario. Si en términos globales el Estado facilita un acceso seguro y equitativo a este derecho o muestra una clara progresión en el estándar general de protección, en algunos casos donde la restricción al derecho no sea muy intensa, podría entrar en juego una "teoría de la neutralización" como la que la Gran Sala usó en Lautsi 2011. Cuando, por el contrario, este nivel general de protección es bajo y el Estado no muestra ninguna progresión al respecto, el Tribunal Europeo de Derechos Humanos tiene razones para ser cada vez más riguroso con las autoridades nacionales en su juicio concreto de proporcionalidad. Esta última situación le exigirá ejercer su rol de garante de la protección efectiva de los derechos convencionales y tendrá que suplir, desde su ámbito de competencia jurisdiccional, la inacción del Estado en el cumplimiento de sus compromisos internacionales. El resumen de esta idea es que a medida que las autoridades nacionales vayan mostrando un mayor nivel de protección general del derecho en cuestión su criterio se vuelve más confiable.

En segundo lugar, el Tribunal Europeo de Derechos Humanos también puede incorporar en su examen de proporcionalidad un método comparativo, prestando atención a cómo actúan otros países europeos

35 En este trabajo me interesan básicamente los conflictos entre derechos convencionales y consideraciones de interés público. No me detendré, por tanto, en los posibles conflictos entre derechos convencionales. 
para analizar si se ha utilizado la mínima coerción posible y si otras alternativas menos gravosas eran viables ${ }^{36}$. Dado que el Convenio Europeo de Derechos Humanos surge para mejorar en conjunto el nivel de protección de derechos humanos en Europa, una razón para poner en duda que el Estado denunciado careciera de otra alternativa menos restrictiva es constatar que otros Estados, en situaciones equiparables, han conseguido la misma finalidad social con medidas diferentes que no han implicado esa restricción del derecho.

En tercer lugar, el estado del consenso europeo en una determinada materia también puede ser relevante para relajar el juicio de proporcionalidad, aunque por razones distintas a las que ofrecería la versión voluntarista. Esta relevancia estará condicionada por la presencia de un vínculo entre la formación de consensos y la dinámica de un progreso paulatino en el sistema general de protección de derechos humanos en Europa $^{37}$. La falta de consenso es un argumento importante para evitar el efecto "sorpresa" que una aplicación alejada del estado de la cuestión en Europa podría provocar. De esta forma, su relevancia depende de un balance entre razones de seguridad jurídica y consideraciones sustantivas en un ajuste mutuo que vaya favoreciendo la consolidación de derechos humanos. Atender a la falta de consenso para ampliar la libertad del Estado resultaría, en cambio, cuestionable si ello acabara redundando en una paulatina disminución del estándar de protección en la región. Aquí la falta de consenso debería carecer de relevancia interpretativa porque solo reflejaría el uso de la versión voluntarista del margen ${ }^{38}$.

En cuarto lugar, la cuestión de si el Estado está realmente mejor situado para decidir también puede ser clave para orientar el juicio de proporcionalidad. Si el Tribunal Europeo de Derechos Humanos

\footnotetext{
36 Véase Arai-Takahashi, Y., ídem.

${ }^{37}$ Sobre la relación entre interpretación evolutiva y consenso europeo, véase Dzehtsiarou, K., "European Consensus and the Evolutive Interpretation of the European Convention on Human Rights", German Law Journal, v. 12, n. 10, 2011, pp. 1730-1745.

${ }^{38}$ Para una visión más crítica del uso del consenso como elemento relevante en la comprensión del CEDH, véase Letsas, G., 2004, ídem.. En contraste, una defensa de que el TEDH debe atenerse generalmente a los consensos puede encontrarse en Hutchinson,
} 160 M., ídem. 
Una versión racionalizada de la doctrina del margen de apreciación estatal

percibe, después de considerarlo detenidamente, que una situación conflictiva no puede ser resuelta de manera adecuada sin un conocimiento profundo de las circunstancias de vida de una sociedad concreta, tiene una razón fuerte para efectuar un escrutinio menos estricto del balance axiológico emprendido por el Estado ${ }^{39}$. Aun así, y centrándonos en la libertad religiosa, esta razón adquiere fuerza solo cuando la imparcialidad del Estado frente a la religión no se haya visto comprometida. Pensemos en casos en los que el Estado tiende a privilegiar la religión mayoritaria o cede ante la presión de la confesión con mayor arraigo. Aquí no parece razonable afirmar que el Estado siga estando mejor situado que un órgano externo para resolver la conflictividad interna que esta falta de imparcialidad pueda comportar ${ }^{40}$. Lo mismo cabría afirmar cuando la medida restrictiva de la libertad religiosa proviene de un Estado confesional o semi-confesional. Cuando el propio Estado mantiene una asimetría entre las diversas religiones practicadas por sus ciudadanos, y esta asimetría ha sido refrendada por sus tribunales internos, no cabe presuponer que las autoridades nacionales están mejor situadas que un órgano internacional para fiscalizar la gestión de su pluralismo religioso interno. Idéntico razonamiento puede ser aplicado cuando el Estado ha optado ideológicamente por un laicismo militante o activo. Un Estado que aboga por una secularización estricta de todo el espacio público tampoco puede ser percibido sin más como un garante imparcial del derecho a la libertad religiosa. Ciertamente, los miembros del Consejo de Europa tienen plena autonomía para decidir cuál será su sistema de relación Estado-iglesia. El pluralismo resultante de ejercer esta autonomía debe poder ser incorporado dentro

${ }^{39}$ Algunos jueces del TEDH, por ejemplo, Rozakis y Spielmann, consideran que este es el elemento determinante para otorgar un margen de apreciación al Estado, especialmente cuando el caso ha sido valorado por sus tribunales internos.

${ }^{40}$ Como observa Mancini, si en estos casos el TEDH otorga un amplio margen de apreciación está en realidad teniendo también un rol contra mayoritario, ya que este órgano fue creado desde el consenso de los Estados para corregir las deficiencias de la democracia mayoritarista. Ver Mancini, S., "The Crucifix Rage: Supranational Constitutionalism Bumps Against the Counter-Majoritarian Difficulty", European Constitutional Law Review, v. 6, 2010, pp. 6-27. 
del marco del Convenio, algo claramente asumido en la jurisprudencia del Tribunal. Sin embargo, cualquier opción estatal en este punto deberá ser compatible con los compromisos internacionales adquiridos por el Estado en lo que atañe a la libertad religiosa de sus ciudadanos. Por esta razón, en todas las situaciones que he mencionado el Tribunal debería ser más estricto en su test de proporcionalidad, ya que adquiere la función de velar por el cumplimiento del grado de neutralidad estatal que sea necesario para la protección efectiva de este derecho convencional. Esta conclusión viene amparada por la propia visión del Tribunal Europeo de Derechos Humanos sobre el rol que corresponde al Estado en la gestión de su pluralismo religioso interno. De un lado, el Tribunal ha resaltado el vínculo entre la libertad religiosa y la democracia, remarcando el papel de este derecho para asegurar el pluralismo inherente a una sociedad democrática ${ }^{41}$. De otro lado, ha insistido en que la responsabilidad del Estado es asegurar, neutral e imparcialmente, el ejercicio de las diferentes religiones y creencias, así como contribuir a mantener el orden público, la armonía religiosa y la tolerancia, especialmente cuando hay grupos en oposición ${ }^{42}$. En este sentido, la idea de que el Estado está mejor situado solo adquiere fuerza si su posición institucional y prácticas previas le permiten ejercer confiablemente esta responsabilidad.

Por último, para que la versión racionalizada del margen constituya un buen recurso hermenéutico en el equilibrio entre democracia y derechos, el Tribunal Europeo de Derechos Humanos debe ser coherente en su utilización y ofrecer pautas generalizables que puedan servir de guía a los Estados y a sus ciudadanos. Ciertamente, el examen de proporcionalidad requiere tomar en consideración el contexto de la medida impugnada. De ahí que el Tribunal no pueda limitarse a efectuar un análisis abstracto de compatibilidad entre el derecho individual y la disposición nacional. Pero también forma parte de la función de Estras-

41 Por ejemplo, asuntos Kokkinakis c. Grecia (25 de mayo de 1993), pár. 31; Manoussakis et al. c. Grecia (29 de agosto de 1996), pár. 44; Serif c. Grecia (14 de diciembre de 1999), pár. 49. 
Una versión racionalizada de la doctrina del margen de apreciación estatal

burgo moldear a través de sus fallos un marco general de comprensión de cada uno de los derechos convencionales. Siguiendo la terminología de Steven Greer, podríamos distinguir dos formas de balance axiológico: a) un balance "ad hoc", donde la ponderación está plenamente centrada en el caso particular, y b) un balance "estructurado", donde la ponderación particular entre derechos e intereses públicos está mediatizada por la pretensión de asentar una doctrina general sobre estándares de protección de derechos en Europa ${ }^{43}$. Este balance estructurado es lo que muchas voces reclaman de Estrasburgo, no solo por razones de racionalidad discursiva, sino por la propia finalidad del Convenio Europeo de Derechos Humanos de obtener una unión más estrecha entre los miembros del Consejo de Europa a través de una concepción y respeto comunes de los derechos humanos. Quienes recelan de que un órgano internacional pueda tener la última palabra en materia de derechos humanos, incluso cuando sus sentencias no posean el mismo valor jurídico que las de los tribunales internos, pueden percibir como una virtud que el Tribunal Europeo de Derechos Humanos se limite a buscar soluciones particulares razonables, desde lógica del caso a caso, más que preocuparse por sentar doctrinas generales. Pero ello acaba erosionando su propia función jurisdiccional de intérprete del Convenio porque le acercan a un simple órgano de arbitraje. El Tribunal Europeo de Derechos Humanos solo puede mantener su legitimidad en tanto institución judicial consolidada si la producción de doctrina es tan importante como la producción de resultados particulares ${ }^{44}$. De esta guisa, su rol es tener un ojo puesto en la cuestión material de equilibrar derechos individuales y valores democráticos en cada supuesto particular y otro ojo puesto en la cuestión estructural de ofrecer respuestas generalizables y estables a nivel europeo. Ello puede evitar las críticas que la jurisprudencia de Estrasburgo ha recibido en materia religiosa por su incoherencia axiológica, su variabilidad de un asunto a otro y su déficit de predictibilidad ${ }^{45}$.

\footnotetext{
${ }^{43}$ Greer, S., ídem.

${ }^{44}$ Véase McHarg, A., ídem.

${ }^{45}$ Brauch, J., ídem.; kratochvíl, J., ídem.
} 
A diferencia de la versión voluntarista, que está abocada a un excesivo particularismo, la versión racionalizada que he defendido tiene la capacidad de ofrecer estándares de protección más generalizables y estables que, al mismo tiempo, atiendan al dualismo axiológico del Convenio. Su adopción por parte del Tribunal de Estrasburgo le dirigiría a valorar las medidas estatales que se impugnan desde parámetros equiparables y con miras a ir construyendo un marco convencional de mínimos en la protección de derechos, un marco que sea lo suficientemente comprensivo como para dar cabida a una pluralidad de finalidades sociales legítimas sin dejar de preservar una mínima calidad sustantiva en los estándares de protección. Siempre que haya una lógica de progresión, el resto del trabajo en la cobertura institucional de los derechos humanos en el seno de Consejo de Europa, así como la decisión sobre cuál es el estándar óptimo de protección más allá de este umbral, será ya una cuestión interna a cada estado.

\section{Los asuntos Lautsi y Şahin desde la versión raciona- lizada del margen de apreciación}

Una vez explorada la dinámica de la versión racionalizada mi sugerencia es utilizarla, aunque sea brevemente, para mostrar por qué la lógica deferente que Estrasburgo empleó en los asuntos Lautsi y Şahin no resulta jurídicamente razonable.

En el asunto Lautsi se produce una afectación al foro interno de la libertad religiosa en aras de preservar una tradición cultural de origen religioso. Aunque la posibilidad de este tipo de afectación carece de apoyo textual en el Convenio, no se trata de una restricción especialmente intensa ya que, ciertamente, el efecto adoctrinador de un crucifijo no es nada obvio si lo comparamos con la imposición de una práctica o actividad religiosa. Parece sensato asumir que el carácter activo o pasivo de un símbolo religioso depende en gran medida de su contexto particular de uso. La cuestión, sin embargo, es si en este asunto hay suficientes razones para apoyar la deferencia al Estado en 
Una versión racionalizada de la doctrina del margen de apreciación estatal

su opción de imponer el crucifijo en las aulas de las escuelas públicas. Utilizando los parámetros anteriores, el argumento de la falta consenso no sería un buen apoyo para esta deferencia. Aunque no hay consenso regulativo en Europa respecto a la simbología religiosa, la imposición del crucifijo es más bien excepcional ya que solo se produce en una minoría de países europeos. Esto disminuye la fuerza de las razones de seguridad jurídica que podrían favorecer al Estado italiano. Además, la falta de homogeneidad regulativa respecto al crucifijo es debida a la presencia de diversos modelos y tradiciones de relación Estado-iglesia en Europa más que a la existencia de un genuino pluralismo valorativo en torno a los límites del derecho a la libertad religiosa individual. Así, esta ausencia de homogeneidad debería jugar un papel menor dentro de la lógica de una consolidación paulatina del derecho a la libertad religiosa en la región.

También cabe dudar de que un Estado cuyas tradiciones culturales privilegian la simbología de una determinada confesión religiosa en detrimento de los no creyentes u otras minorías religiosas esté realmente mejor situado para resolver de forma imparcial los conflictos que el uso institucional de esta simbología ha generado. En este sentido, ni el argumento de la falta de consenso ni la idea de la mejor situación del Estado justificarían en este caso otorgar una deferencia amplia, teniendo en cuenta, asimismo, que la normativa italiana tiene un pedigrí democrático débil al provenir principalmente de reglamentaciones de los años veinte, del período fascista, carecer de confirmación parlamentaria y no haber sido valorada por el Tribunal Constitucional italiano ${ }^{46}$.

A partir de aquí cabe preguntarse si el Estado italiano ha utilizado el mecanismo menos restrictivo posible en su afectación al foro interno de la libertad religiosa para mantener sus tradiciones culturales. Como el Tribunal Europeo de Derechos Humanos ha reconocido acertadamente, mantener las tradiciones culturales es algo que forma parte de

46 Véase, a este respecto, el voto disidente a Lautsi 2011, pár. 1. Curiosamente, dado que este asunto no fue analizado siguiendo los pasos de la cláusula de acomodación del art. 9.2, el TEDH se ahorró de tener que valorar si la medida estaba prevista por un Derecho de mínima calidad. 
los fines legítimos de un Estado democrático ${ }^{47}$. Pero la cuestión es si el Estado italiano no disponía de otras alternativas menos gravosas que no implicaran renunciar a este objetivo y si ha ejercido la mínima coerción posible. Utilizando el método comparativo, parece falso que no haya otras alternativas para mantener la tradición cultural del crucifijo en Italia. De hecho, en España, Grecia, Irlanda o San Marino, que no poseen una regulación expresa, este símbolo sigue estando presente en algunas escuelas públicas. La imposición normativa no resulta entonces necesaria (o al menos el Estado italiano no ha probado esa necesidad en su coyuntura social). La imposición normativa tampoco es seguramente el mejor medio para mantener las tradiciones culturales de una sociedad democrática. La persistencia de las tradiciones está vinculada a muchos factores entrelazados y, en gran parte, depende de su arraigo popular y de la existencia de un sustrato social basado en la tolerancia y el respeto mutuos. Dado que hay otras opciones menos gravosas y coercitivas, la desproporción de una medida que afecta al foro interno difícilmente puede compensarse con una apertura al pluralismo religioso en otras esferas educativas, con lo que una teoría de la neutralización adquiere poca fuerza en este caso. Lo que realmente parece estar en juego, entonces, es la voluntad del Estado italiano expresada en el recurso a Lautsi 2009, extremo que, como he comentado más arriba, no tiene valor por sí mismo desde una versión racionalizada del margen de apreciación.

Ello no implica, en mi opinión, que la única opción compatible con el Convenio Europeo de Derechos Humanos sea la prohibición de exhibir el crucifijo u otros símbolos religiosos en las paredes de las escuelas públicas. Aunque no podré desarrollar este punto, la versión racionalizada también permitiría mostrar que el análisis abstracto de compatibilidad efectuado por la Sala del Tribunal Europeo de Derechos Humanos en Lautsi 2009 es claramente deficiente por su opacidad a los factores de contexto. La conclusión de vulneración del Convenio no depende meramente de que esta simbología esté presente en escuelas públicas y de su "potencial" capacidad de afectación. Lo relevante 
Una versión racionalizada de la doctrina del margen de apreciación estatal

es qué tipo de intervención ha tenido el Estado en la presencia de esta simbología. Por esta razón, desde una versión racionalizada habría razones para defender la compatibilidad convencional de otras opciones regulativas distintas a la imposición o de soluciones contextuales a la polémica del crucifijo en las aulas ${ }^{48}$.

En lo que atañe al asunto Şahin diría que estamos ante una restricción más intensa aunque en este caso afecta al foro externo de la libertad religiosa, derecho que según el art. 9.2 es limitable por otras consideraciones de interés público. La cuestión vuelve a ser aquí si poseemos razones para otorgar deferencia al criterio estatal. En contraste con lo que sucede en Italia respecto a la exhibición del crucifijo, las prohibiciones del uso del velo islámico en Turquía están apoyadas en el principio constitucional del laicismo de Estado y esta opción regulativa goza del refrendo de su Tribunal Constitucional. Pero las razones para la deferencia al Estado en el caso de la restricción del velo en la universidad son todavía más débiles que en el asunto Lautsi. Por lo que respecta al consenso europeo, en prácticamente ningún Estado miembro del Consejo de Europa se impide el uso del velo en los centros universitarios, y es razonable afirmar que atender a ese consenso contrario favorece la protección del derecho a la libertad religiosa en la región ${ }^{49}$. Es más, me atrevería a indicar que la tendencia prohibitiva que está avanzando en algunos países europeos ha sido incentivada, al menos en parte, por la gran deferencia que el Tribunal Europeo de Derechos Humanos ha mostrado con estas restricciones a la libertad religiosa iniciadas en Francia y Turquía ${ }^{50}$.

48 Sobre estas opciones, véase Iglesias Vila, M. y Ungureanu, C., ídem.

49 Aunque el Tribunal utilizó en este caso el argumento de la falta de consenso europeo en la regulación del uso del velo para ampliar el margen de apreciación del Estado, su estrategia es tramposa porque atiende a la regulación general sobre simbología religiosa, donde no hay homogeneidad, sin mencionar que hay un consenso contrario en Europa respecto a la concreta regulación impugnada.

${ }^{50}$ En este trabajo no entraré en otros asuntos más recientes en materia de simbología religiosa porque no están vinculados al espacio educativo. Me refiero a los asuntos Eweida et al. c. Reino Unido (31 de enero de 2013) y S.A.S. c. Francia (1 de julio de 2014, GS). Respecto de este último asunto, cabe destacar que Estrasburgo todavía ha ampliado más el margen de apreciación del Estado francés para restringir la 
El argumento de que el Estado está mejor situado para decidir sobre la conveniencia de limitar el uso del velo en la universidad tampoco es un buen aliado para justificar la deferencia al Estado turco. Como observaba anteriormente, el laicismo de Estado es una opción política legítima pero no imparcial frente al pluralismo religioso en una sociedad democrática. Ante esta opción política, igual que ante la opción institucional por el Estado confesional, el Tribunal Europeo de Derechos Humanos adquiere un rol cualificado de vigilancia para impedir que este modelo de relación Estado-religión vaya en detrimento del cumplimiento de los compromisos internacionales del Estado en el respeto a los derechos convencionales. Al mismo tiempo, esta opción por el laicismo activo viene habitualmente acompañada de un estándar bajo de protección general de la libertad de manifestación religiosa en el espacio público, con lo que hay pocos argumentos para confiar sin más en el criterio estatal. La forma de llevar a cabo esta supervisión es efectuar un test estricto de proporcionalidad o, al menos, entrar en una valoración detallada de proporcionalidad.

En este examen de proporcionalidad, el Tribunal Europeo de Derechos Humanos debería haber comprobado de forma pormenorizada si las razones aportadas por el Estado turco para prohibir el velo en la universidad eran convincentes ${ }^{51}$. Por una parte, la presencia de un

libertad personal para usar simbología religiosa en el espacio público. Aunque el asunto atiende a un tipo de prenda religiosa en particular, el velo integral, el Tribunal considera, variando aquí su anterior línea jurisprudencial, que todos los argumentos que se han aportado hasta ahora para prohibir el velo en el ámbito educativo carecen de fuerza argumentativa para justificar esta medida coercitiva. Sin embargo, la conclusión implícita que cabe extraer de la ratio decidendi de la sentencia es que el margen de apreciación nacional es tan amplio en esta materia que los Estados ni siquiera requieren el apoyo de estos débiles argumentos. Para ampliar este margen y justificar la prohibición del uso del velo integral en los espacios públicos el Tribunal se ha basado en algo tan difuso y oscuro como es el valor de la vida en común que la sociedad francesa tendría derecho a preservar, valor que Estrasburgo incorpora en las finalidades legítimas previstas en el artículo 9.2 a través de la finalidad de proteger los derechos y libertades de los demás.

${ }^{51}$ A partir del asunto S.A.S. c. Francia, este extremo resulta todavía más obvio desde el momento en que, como destaco en la nota anterior, el Tribunal ha descartado una por una la mayoría de razones que suelen aportarse para justificar la prohibición del 
Una versión racionalizada de la doctrina del margen de apreciación estatal

principio constitucional de laicidad no es determinante ni resulta suficiente ya que, usando el método comparativo, incluso en Francia, que también acoge este modelo estatal, el laicismo se sigue manteniendo sin esta restricción a la libertad religiosa en los centros universitarios ${ }^{52}$. En este sentido, apelar al principio de laicidad no libera al Estado de la obligación convencional de demostrar que existe una "necesidad social imperiosa" que justifique la restricción de esta prenda en sede universitaria. Si esta prueba no se ofrece, resultará falso que el Estado carecía de otra alternativa menos coercitiva para obtener sus finalidades legítimas con la misma eficacia.

Algo parecido sucede con el resto de los argumentos generales que aportó Turquía para defender la prohibición, que se basan en conexiones hipotéticas entre el uso del velo y el fomento del radicalismo islámico, la promoción de la discriminación de género y los riesgos para la democracia en Turquía. El Tribunal Europeo de Derechos Humanos debería haber analizado con detalle la solidez de tales conexiones y si estas avalan el uso de la coerción institucional en la universidad. De la misma forma, el Tribunal de Estrasburgo debería haber entrado a valorar si en el caso concreto de Leyla Şahin estas alegaciones resultaban convincentes. Como observa acertadamente la jueza Tulkens en su voto disidente en este asunto, el Estado no mostró en ningún momento que el uso del velo por parte de una persona adulta como Leyla Şahin fuera forzado o la subordinara como mujer. Tampoco había ningún indicio de que Şahin hubiera vestido esta prenda con alguna finalidad de presión política extremista ni que su uso por parte de esta estudiante hubiera generado alteraciones del orden público o pretendido influir en el resto de estudiantes o limitar alguno de sus derechos. En suma, y dejado ahora al margen otras cuestiones de interés, la resistencia del Tribunal de Estrasburgo a entrar a valorar estos argumentos en el

uso de prendas de carácter religioso. El Tribunal ha admitido que estas razones son demasiado débiles para justificar una restricción al derecho convencional de libertad religiosa.

52 Aunque gracias, seguramente, a la laxitud del Tribunal Europeo en esta cuestión, la posibilidad de prohibir el uso del velo islámico en la universidad ha entrado en el debate político francés. 
caso concreto supone una dejación de funciones jurisdiccionales en la protección del derecho humano a la libertad religiosa de la recurrente y solo es explicable desde una versión voluntarista.

A mi juicio, si el Tribunal Europeo de Derechos Humanos hubiera adoptado una versión racionalizada en su jurisprudencia en torno a la simbología religiosa en el contexto educativo habría ejercido de forma más satisfactoria su rol jurisdiccional dentro de la lógica dual del Convenio Europeo de Derechos Humanos, construyendo un marco más estable y coherente de mínimos convencionales en torno a las exigencias de este derecho humano. Ciertamente, la interpretación y aplicación de convenios internacionales de derechos humanos es una actividad especialmente delicada, y el Tribunal Europeo de Derechos Humanos es una institución que tiene la difícil tarea de proteger derechos moviéndose entre aguas valorativas revueltas y presiones políticas de alto nivel. Pero la concesión política permanente a los Estados en conflictos religiosos de carácter sensible no conseguirá a la larga que el Tribunal de Estrasburgo mantenga su "auctoritas" institucional en Europa porque, cuando alguien te da casi siempre la razón, incluso cuando no debería, acabas pensando que solo son tus razones las que importan.

\section{Conclusión}

Mi objetivo en este trabajo ha sido mostrar que la inclusión de una referencia expresa a la doctrina del margen de apreciación estatal en el preámbulo del Convenio Europeo de Derechos Humanos no tiene por qué suponer un retroceso para los derechos humanos en Europa. Pero solo podremos garantizar que esta doctrina sirve a la función jurisdiccional que corresponde a Estrasburgo en la protección regional de estos derechos, si es consistente con la base axiológica que da sentido al Convenio en tanto instrumento internacional. Utilizando como ejemplo la jurisprudencia del Tribunal sobre simbología religiosa en los centros docentes, he sugerido que deberíamos abogar por una versión racionalizada de esta doctrina, que combine los elementos necesarios para contribuir a un equilibrio ponderado entre pluralismo democrá- 
Una versión racionalizada de la doctrina del margen de apreciación estatal

tico y comprensión unitaria de los derechos humanos en el seno del Consejo de Europa. Esperemos que el Tribunal de Estrasburgo sepa leer el nuevo preámbulo como una invitación a seguir reforzando este balance y no como una rendición solapada a las exigencias coyunturales de la facticidad política.

\section{Bibliografía}

Alexy, R., Teoría de los derechos fundamentales, Madrid: Centro de Estudios Políticos y Constitucionales, 1993.

Andreescu, G. y Andreescu, L., "Taking Back Lautsi: Towards a 'Theory of Neutralisation'?", Religion and Human Rights, 2010, pp. 207-212.

Andreescu, G. y Andreescu, L., "The European Court of Human Rights' Lautsi Decision: Context, Contents, Consequences”, Journal for the Study of Religions and Ideologies, v. 9, n. 26, 2010, pp. 47-74.

Arai-Takahashi, Y., The Margin of Appreciation Doctrine and the Principle of Proportionality in the Jurisprudence of the ECHR, Oxford: Intersetia, 2002.

Barak, A., Proportionality: Constitutional Rights and their Limitations, Cambridge: Cambridge University Press, 2012.

Baynes, K., "Towards a Political Conception of Human Rights", Philosophy and Social Criticism, n. 35, 2009, pp. 372-373.

Beitz, Ch., The Idea of Human Rights, Oxford: Oxford University Press, 2009.

Brauch, J., "The Margin of Appreciation and the Jurisprudence of the European Court of Human Rights: Threat to the Rule of Law", Columbia Journal of European Law, v. 11, 2005, pp. 113-150.

Brems, E., "Human Rights: Minimum and Maximum Perspectives", Human Rights Law Review, v. 9, n. 3, 2009, pp. 349-372.

Contesse, J., "Subsidiarity in Inter-American Human Rights Law", SELA paper, 2015. www.law.yale.edu/system/files/documents/ pdf/SELA15_Contesse_CV_Eng.pdf. 
Marisa Iglesias Vila

Dworkin, R., Taking Rights Seriously, Cambridge: Harvard University Press, Mass, 1977.

Dzehtsiarou, K., "European Consensus and the Evolutive Interpretation of the European Convention on Human Rights", German Law Journal, v. 12, n. 10, 2011, pp. 1730-1745.

Evans, C., Freedom of Religion under the European Convention on Human Rights, Oxford: Oxford University Press, 2001.

Føllesdal, A., "The Principle of Subsidiarity as a Constitutional Principle in International Law", Global Constitutionalism, v. 2, n. 1, 2013, pp. 37-62.

Gerards, J., "Pluralism, Deference and the Margin of Appreciation Doctrine", European Law Journal, v. 17, n. 1, 2011, pp. 80-120.

Greer, S., "Constitutionalizing Adjudication under the European Convention on Human Rights", Oxford Journal of Legal Studies, v. 23, n. 3, 2003, pp. 405-433.

Greer, S., "'Balancing' and the European Court of Human Rights: A Contribution to the Habermas-Alexy Debate", Cambridge Law Journal, v. 63, n. 2, 2004, pp. 412-434.

Hutchinson, M., "The Margin of Appreciation and the Jurisprudence of the European Court of Human Rights", International and Comparative Law Quarterly, v. 48, n. 3, 1999, pp. 638-650.

Iglesias Vila, M. y Ungureanu, C., "The Conundrum of Pluralism and the Doctrine of the Margin of Appreciation: The Crucifix 'Affair' and the Ambivalence of the ECtHR", en Requejo, F. y Ungureanu, C. (eds.), Democracy, Law and Religious Pluralism in Europe: Secularism and Post-Secularism, Londres: Routledge, 2012, pp. 179-199.

Iglesias Vila, M., "La aplicación del CEDH desde una concepción política de los derechos humanos: algunas claves interpretativas", en Arcos, F. (ed.), La justicia y los derechos en un mundo globalizado, Madrid, Dykinson, 2016, pp. 166-191.

Klatt, M. y Meister, M., The Constitutional Structure of Proportionality, Oxford: Oxford University Press, 2012.

Kratochvíl, J., "The Inflation of the Margin of Appreciation by the European Court of Humans Rights", Netherlands Quarterly of Human Rights, v. 29, n. 3, 2011, pp. 324-357. 
Una versión racionalizada de la doctrina del margen de apreciación estatal

Kumm, M., "What Do You Have in Virtue of Having a Constitutional Right? On the Place and Limits of the Proportionality Requirement", en Paulsen, S. y Pavlakos, G. (eds.), Law, Rights, and Discourse: Themes of the Work of Robert Alexy, Oxford: Hart Publishing, 2007.

Legg, A., The Margin of Appreciation in International Human Rights Law: Deference and Proportionality, Oxford: Oxford University Press, 2012. Letsas. G., "The Truth in Autonomous Concepts: How To Interpret the ECHR", European Journal of International Law, v. 15, n. 2, 2004, pp. 279-305.

Letsas, G., "Two Concepts of the Margin of Appreciation", Oxford Journal of Legal Studies, v. 26, n. 4, 2006, pp. 705-732.

Mahoney, P., "Marvelous Richness of Diversity or Invidious Cultural Relativism?", Human Rights Law Journal, v. 19, 1998.

Mancini, S., "The Crucifix Rage: Supranational Constitutionalism Bumps Against the Counter-Majoritarian Difficulty", European Constitutional Law Review, v. 6, 2010, pp. 6-27.

Martínez-Torrón, J., "Los límites de la libertad de religión y de creencia en el Convenio Europeo de Derechos Humanos", RGDCDEE, $\mathrm{n}$. 2, 2003.

Martínez-Torrón, J., "The (Un)protection of Individual Religious Identity in the Strasbourg Case Law", Oxford Journal of Law and Religion, (Advance Access), 2012, pp. 1-25.

McGoldrick, D., "Religion in the European Public Square and in European Public Life-Crucifixes in the Classroom?", Human Rights Law Review, v. 11, n. 3, 2011, pp. 451-502.

McHarg, A., "Reconciling Human Rights and the Public Interest: Conceptual Problems and Doctrinal Uncertainty in the Jurisprudence of the European Court of Human Rights", The Modern Law Review, v. 62, 1999, pp. 671-696.

Nuñez Poblete, M. y Acosta Alvarado, P. A., El margen de apreciación en el sistema interamericano de derechos humanos: proyecciones regionales y nacionales, México, UNAM, 2012.

Panara, C., "Another Defeat for the Principle of Secularism: Recent Developments on the Display of the Crucifix in Italian Courtrooms", Religion and Human Rights, v. 6, n. 3, 2011, pp. 259-265. 
Raz, J., "Human Rights without Foundations", Oxford Legal Studies Research Papers, n. 14, 2007, pp. 1-20.

Raz, J., "Human Rights in the Emerging World Order", Transnational Legal Theory, n. 1, 2010, pp. 31-47.

Solar, J. I., "Cautelas y excesos en el tratamiento del factor religioso en la jurisprudencia del Tribunal Europeo de Derechos Humanos", Derechos y libertades, n. 20, 2009, pp. 117-161.

Spielmann, D., "Allowing the Right Margin the European Court of Human Rights and the National Margin of Appreciation Doctrine: Waiver or Subsidiarity of European Review?", CELS Working Paper Series, 2012, pp. 1-30.

Zuca, L., "Lautsi: A Commentary on a Decision by the ECtHR Gran Chamber", International Journal of Constitutional Law, v. 11, n. 1, 2013, pp. 218-229. 